\title{
Phonological processing in children with specific language impairment with and without reading difficulties
}

Article

Accepted Version

Loucas, T., Baird, G., Simonoff, E. and Slonims, V. (2016) Phonological processing in children with specific language impairment with and without reading difficulties. International Journal of Language and Communication Disorders, 51 (5). pp. 581-588. ISSN 1460-6984 doi:

https://doi.org/10.1111/1460-6984.12225 Available at https://centaur.reading.ac.uk/47619/

It is advisable to refer to the publisher's version if you intend to cite from the work. See Guidance on citing.

To link to this article DOI: http://dx.doi.org/10.1111/1460-6984.12225

Publisher: Wiley

All outputs in CentAUR are protected by Intellectual Property Rights law, including copyright law. Copyright and IPR is retained by the creators or other copyright holders. Terms and conditions for use of this material are defined in the End User Agreement. 


\section{CentAUR}

Central Archive at the University of Reading

Reading's research outputs online 
Phonological processing in children with specific language impairment with and without reading difficulties

RUNNING HEAD: Phonological processing, language impairment and reading

KEY WORDS: SLI, reading, phonological processing 


\begin{abstract}
Background: SLI is heterogeneous and identifying subgroups within it may help explain the aetiology of the condition. Phonological processing abilities distinguish between children with SLI who do and do not have reading decoding impairments (RDI).

Aims: This study aims to probe different levels of phonological processing in children with SLI with and without RDI to investigate the cognitive basis of these differences.

Methods \& Procedures: 64 children aged 5-17 years were classified using the results of standardised language and single-word reading tests into those with no SLI and no RDI (No-SLI/No-RDI) $(\mathrm{N}=18)$, no SLI but with RDI (No-SLI/RDI) $(\mathrm{N}=4$, not included in analyses because of the small number), SLI/No-RDI $(\mathrm{N}=20)$ and SLI/RDI $(\mathrm{N}=22)$. The groups were compared on a range of tasks engaging different levels of phonological processing (input and output processing and phonological awareness).

Outcomes \& Results: The SLI/RDI group was distinguished from the SLI/No-RDI and No- SLI/No-RDI groups by more errors in the longer items in nonword repetition and by poorer phonological awareness. Nonword discrimination scores indicated a gradient of performance across groups, which was not associated with a qualitatively different pattern of performance.
\end{abstract}

Conclusions \& Implications: This is the first study contrasting input and output processes associated with phonological processing. The results suggest that deficits in SLI plus RDI may be associated with impairment in actively maintaining phonological representations for phonological processing, which is not present in those without RDI and which leads to reading decoding difficulties. 


\section{INTRODUCTION}

Specific language impairment (SLI), a deficit in spoken language which cannot be explained by hearing loss, neurological impairment or intellectual disability, is heterogeneous and identifying subgroups within it may help uncover the aetiology of the condition. Many, but not all, children with SLI have phonological processing difficulties. Understanding the nature of these difficulties can lead to a better characterisation of the underlying cognitive basis of SLI which can in turn support investigations into the neurobiological and genetic causes of the condition.

The term phonological processing covers a range of cognitive processes from those underlying speech perception to the metacognitive processes involved in phonological awareness. Wagner and Torgesen (1987) describe several components of phonological processing: (i) storing phonological information in short term memory (i.e., phonological short term memory (PSTM)), measured by tasks such as nonword repetition (NWR); (ii) retrieving phonological information from long term memory, measured by rapid naming of object pictures, letters or numerals; and (iii) phonological awareness (i.e., awareness of the sound structure of spoken words), measured by tasks requiring the manipulation of the soundstructure words; for example, elision, where the child is asked to say "What is cat without the /k/". Wagner and Torgesen (1987) argued that phonological processing plays a causal role in learning to read. For example, they cite evidence that phonological awareness and reading are related independent of general cognitive ability and that good and poor readers differ on memory span tasks, with these differences derive primarily from differences in the efficiency of phonetic recoding in working memory. A weakness in phonological skills is now seen as the principle cause of reading decoding impairment (dyslexia), which can be contrasted with reading comprehension difficulties (Snowling \& Hulm, 2012). Snowling and Hulme (2012) suggest that a phonological deficit will have a direct causal influence on learning to read 
because it will impact on the child's ability learn mappings between the visual, written, form of words and their spoken form (i.e., between graphemes and phonemes). They argue a phonological deficit can account for evidence that verbal short-term memory impairments, reflecting phonological coding deficits, and impairments in rapid naming, reflecting deficits in mapping between phonological and visual representations, are associated with reading decoding impairment (RDI).

Thus, impaired phonological processing has been implicated in RDI and it has also been implicated in SLI. A reduced ability to repeat nonwords is found in children with RDI without language impairment (Melby-Lervåga \& Lervåga, 2012). As nonword repetition is a measure of PSTM, one of Wager and Torgesen's (1987) markers of phonological processing, these difficulties are consistent with a phonological processing deficit. Many children with SLI have a similar difficulty with nonword repetition (NWR). In a twin study of SLI, and Bishop, Donlan and North (1996) found NWR performance to be highly heritable and proposed it as a clinical marker of SLI. However, some children with SLI do not have NWR deficits (Baird, Slonims, Simonoff \& Dworzynski, 2011; Bishop, McDonald, Bird \& HayiouThomas, 2009; Catts, Adolf, Hogan \& Weismer, 2005). In a large sample of children with SLI, Baird et al. (2011) found RDI in two-thirds and in those with poor reading decoding (i.e., difficulties mapping from orthography to phonology) NWR was impaired. Other studies also report poor NWR in children with SLI plus RDI compared to those with SLI only (Bishop, et al., 2009; Catts, et al., 2005). This may indicate that NWR is a marker for processes associated with reading rather than language impairment. Children with SLI plus RDI perform more poorly on phonological awareness tasks (Catts et al., 2005) and show mild impairments in rapid naming (Bishop et al., 2009) compared to children with SLI only.

In addition to the processes outlined by Wager and Torgesen (1987), the phonological processes impaired in SLI and RDI, and tasks used to measure them such as 
NWR, must draw on other aspects of processing including those underlying speech perception and spoken word recognition. Deficits in these early stage processes could account for poor performance on higher-level phonological processing, including metacognitive processes. Reviewing the evidence, Rosen (2003) concluded that while some general auditory perceptual processes are impaired in SLI, only a minority of individuals show deficits. Furthermore, when they occur deficits are not specific to speech, and there is little or no relationship between the severity of auditory and language deficits. The evidence for auditory perceptual deficits specific to speech is also equivocal. Montgomery (1995) found differences between children with SLI and language-matched controls in discrimination of four-syllable nonwords. Marton and Schwartz (2003) did not replicate this finding, but they used stimuli differing in stress pattern which may have been easier for children with SLI to discriminate, compared to Montgomery's stimuli which differed by single phonemes. At a more basic level, categorical perception for tokens of natural speech in children with SLI is comparable to age-matched controls when the task demands minimize memory load (Coady, Kluender \& Evans, 2005). This may indicate that poor performance on speech perception tasks is a consequence of task complexity, including PSTM load, and not a speech perception deficit.

Loucas et al. (2010) investigated the input components of NWR using a speeded nonword discrimination task (NWD). Adolescent listeners were asked to make a same/different judgement about pairs of nonwords which manipulated the PSTM load by contrasting 2- and 4-syllable nonwords and the speech perception load by varying the point in the nonword where a single phonetic feature difference occurred. Reaction times showed an interaction between increasing speech perception and PSTM load, which was similar for participants with and without language impairment, consistent with Coady et al.'s (2005) suggestion. The similar pattern of performance across the groups may indicate that 
phonological input processes, including speech perception, are relatively intact in adolescents with SLI and deficits in NWR lie at other levels of the system. In particular, NWR must involve phonological output processes, not engaged in a discrimination task, which could, at least in part, account for poor performance.

Thus, phonological tasks can be conceived of as tapping different levels of processing. Nonword discrimination (NWD) engages phonological input processes and NWR engages both input and output processes. Phonological awareness (PA) is a metacognitive task which involves the explicit manipulation of phonological output representations. Therefore, NWD, NWR and PA are a series of partially overlapping tasks which engage progressively more explicit and metalinguistic aspects of phonological processing. The evidence reviewed suggests that some but not all children with SLI have some deficits in phonological processing which is likely to be associated with RDI and that other children with SLI do not appear to have phonological processing deficits or reading decoding impairment. This study aims to investigate which levels of phonological processing, including input, output and metacognitive skills, are impaired in children with SLI with and without RDI and without SLI or RDI.

\section{METHODS}

\section{Participants}

The children in this study were drawn from a sample recruited for a study of the genetics of language impairment (for details see Baird et al., 2011). Ethical approval for the study was granted by the Guy's Research Ethics Committee and informed consent given by parents and, where appropriate, children. Participants in this study were selected if they had completed a nonword discrimination task (Loucas et al., 2010). The 64 children had a mean age of 10.9 years $(\mathrm{SD}=2.9$; range 5.0 to 17.0 years $)$. The children were from 47 different 
families; 68\% (N=32) were families with a single child participating, 27\% (N=13) with two children participating, $4 \%(\mathrm{~N}=2)$ with three children participating.

\section{Measures}

Wechsler Intelligence Scale for Children III (WISC-III) and Clinical Evaluation of Language Fundamentals (CELF 3rd or 4th UK Editions, or CELF-Preschool UK Edition) were used to evaluate the children's cognitive and language abilities. The Test of Word Reading Efficiency (TOWRE) was used to identify RDI. Input phonological processing, including speech perception and PSTM, was measured using an experimental measure, the nonword discrimination task (NWD). The NWD task involved children listening to pairs of nonwords and making same/different judgments. The nonwords were constructed to vary PSTM and speech perceptual demands. PSTM demands were manipulated by contrasting two- and four-syllable nonwords and speech perceptual demands were manipulated by contrasting nonword pairs that differed on a single phoneme in word-initial or within-word positions (full details can be found in Loucas et al., 2010). Output phonological processing, including PSTM, was assessed using the Children's Test of Nonword Repetition (CNRep, from the Working Memory Test Battery for Children; Gathercole \& Pickering, 2001). Phonological awareness was assessed using a subtest of the Comprehensive Test of Phonological Processing which comprised of elision and blending (CTOPP; Rashotte, Torgesen \& Wagner, 1999).

\section{Classification of children for analysis}

Children were classified as having language impairment (SLI) if they achieved scores below 77 on the Receptive, Expressive or Total Language scales of the CELF and a performance IQ of at least 80. Twenty-two children were classified as No-SLI and 42 with SLI. They were classified as having a reading disability (RDI) if they scored below 77 on the Sight Word Efficiency (real words) subtest and the Phonetic Decoding Efficiency (pseudo- 
words) of the TOWRE ( 9 children did not complete the TOWRE because of time limitations during the data collection, in this case the real word and pseudo-word decoding subtest scores of the WIAT were used). Thirty-eight children were classified as No-RDI and 26 as RDI. SLI and RDI status was used to group children as No-SLI/No-RDI ( $\mathrm{N}=18$ ), No-SLI/RDI (N $=4), \mathrm{SLI} / \mathrm{No}-\mathrm{RDI}(\mathrm{N}=20)$ and SLI/RDI $(\mathrm{N}=22)$.

\section{Analysis}

As $2.6 \%$ of the data were missing (including 3\% for CNRep and $17 \%$ for CTOPP), a missing values analysis was completed in SPSS 21. Little's MCAR test demonstrated the missing values were missing at random and the expectation-maximization (EM) method was used to generate a complete dataset using likelihood minimisation. The analyses for the complete EM dataset are reported below and note made where there were differences with the original dataset. As the No-SLI/RDI category only contained 4 children, this group was not included in the analyses. Liner mixed effects models (LMMs) were used to explore betweengroup differences for all measures with score as the dependent variable, group as the between-subjects factor and family identifier nested within it as a random effect.

\section{RESULTS}

Descriptive statistics for the original and imputed datasets are presented in Table 1 and the results of the LMMs for each of the measures are reported in Table 2.

---- Table 1 about here ----

Overall there was a significant difference in PIQ between the groups $(F(2,52)=4.309$, $\mathrm{p}=.019)$ and so PIQ was included as a covariate in the subsequent analyses. The NoSLI/No-RDI group achieved higher PIQ (Mean $=107.61 ; \mathrm{SD}=12.07)$ than the SLI/RDI group $($ Mean $=97.32 ; \mathrm{SD}=12.16)$, but it did not differ from the SLI/No-RDI group $($ Mean $=$ 96.85; SD =13.39) and both SLI groups performed at a similar level. The No-SLI/No-RDI group $($ Mean $=11.10$ years; $\mathrm{SD}=3.26)$ were older than both the SLI/No-RDI group $($ Mean $=$ 
10.49 years; $\mathrm{SD}=2.60)$ and the SLI/RDI group $($ Mean $=10.75$ years; $\mathrm{SD}=2.82)$. These differences were not significant $(\mathrm{F}(2,53)=0.164, \mathrm{p}=.849)$, but because of the wide age range across the sample (from 5 to 17 years) age was also included as a covariate in the analyses. Planned comparisons between groups were completed using Tukey's LSD.

---- Table 2 about here ----

As expected, for the spoken language measures used to define the groups (CELFRLS, CELF-ELS, CELF-CLS) the No-SLI/No-RDI group had significantly higher scores than both language impaired groups. The SLI/No-RDI and SLI/RDI groups did not differ on the receptive and expressive scales of the CELF, but pairwise comparisons revealed the higher composite language score achieved by the SLI/No-RDI group (Mean $=67.00, \mathrm{SD}=$ 8.92) compared SLI/RDI (Mean $=60.64, \mathrm{SD}=4.43)$ was significant (see Table 2$)$. For real word and nonword reading, again used to define the groups, the SLI/RDI group showed significantly poorer performance than the two groups without RDI; the latter did not differ from each other.

There was a significant difference in NWD scores between the groups which was driven by the No-SLI/No-RDI group achieving a higher score than SLI/RDI group. Other pairwise comparisons were not significant. The pattern of performance for NWD was further investigated in a LMM with stimulus length (2-syllable/4-syllable) and mismatch position (word-initial/word-medial) as within-subject factors, diagnostic group (No-SLI/No-RDI, SLI/No-RDI, SLI/RDI) as a between-subjects factor. Again Age and PIQ were included as covariates and Family nested with diagnostic group as a random factor. Mean number correct by condition for each group is shown in Table 2. There were main effects for nonword length $(\mathrm{F}(1,171)=11.111, \mathrm{p}=.001)$, a marginal effect of mismatch position $(\mathrm{F}(1,171)$ $=3.607, \mathrm{p}=.059)$ and a significant interaction between these factors $(\mathrm{F}(1,171)=14.583$, $\mathrm{p}<.001)$. There was an effect of diagnostic group $(\mathrm{F}(2,55)=3.945, \mathrm{p}=.025)$ but no 
interaction between diagnostic group and the stimulus manipulations $(F(1,171)=0.403$, $\mathrm{p}=.669)$. Age was significant covariate $(\mathrm{F}(1,55)=6.207, \mathrm{p}=.016)$ but not PIQ $(\mathrm{F}(2,55)=$ $0.566, \mathrm{p}=.455$ ) the effect of family nested in group was significant (Wald $\mathrm{Z}=4.464, \mathrm{p}<.001$ ).

---- Table 3 about here ----

For CNRep the No-SLI/No-RDI and SLI/ No-RDI groups both achieved higher scores than the SLI/RDI group; the No-SLI/No-RDI and SLI/ No-RDI groups did not differ. A further analysis of the CNRep data was conducted looking at the results for 2-, 3-, 4- and 5syllable items using a series of LMMs with diagnostic group as a between-subjects factor, Age and PIQ included as covariates and Family nested in diagnostic group as a random factor. There was an effect of diagnostic group for 4- and 5-syllable nonwords (4-syllable: $\mathrm{F}(2,45)=11.907, \mathrm{p}<.001 ; \mathrm{PIQ}, \mathrm{F}(1,44)=0.415, \mathrm{p}=.523 ;$ Age, $\mathrm{F}(1,55)=23.715, \mathrm{p}<.001 ;$ Family, Wald Z=0.839, p=.402; 5-syllable: $F(2,51)=5.819, p=.005 ; P I Q, F(1,51)=0.108$, $\mathrm{p}=.743$; Age, $\mathrm{F}(1,55)=12.738, \mathrm{p}=.001$; Family, Wald $\mathrm{Z}=1.468, \mathrm{p}=.142)$. There was no effect of group for 2- or 3-syllable nonwords $(F(2,51)=2.210, p=.120$ and $F(2,57)=2.403, p=$ .100 respectively). Planned pairwise comparisons using Tukey's LSD revealed that the SLI/RDI group made more errors on both 4- and 5-syllable nonwords than either the NoSLI/No-RDI or SLI/No-RDI groups; the No-SLI/No-RDI and SLI/No-RDI groups did not differ (see Figure 1).

---- Figure 1 about here ----

The No-SLI/No-RDI and SLI/No-RDI both showed low average performance on the phonological awareness subtest of the CTOPP. The SLI/RDI group's score indicated a severe impairment and was significantly lower than both other groups (see Tables 1 and 2).

\section{DISCUSSION}

This study investigated phonological processing in children with SLI, contrasting those with and without RDI. Children with SLI plus RDI have difficulties in tasks tapping 
different aspects of phonological processing, phonological awareness and NWR where children with SLI only do not. The results presented here are consistent with the findings of Catts et al. (2005), Bishop et al. (2009) and Baird et al. (2011).

There was a different pattern of performance in SLI groups across NWD and CNRep even though both tasks require listeners to process nonword strings of differing length, and so ostensibly make similar phonological processing demands. It was the stimulus properties, namely nonword length, which differentiated the groups. Overall scores on NWD indicated a gradient of performance across groups. The children in the SLI/RDI group achieved lower scores than those in the NoSLI/NoRDI group, with the SLI/NoRDI group lying between the other two groups, not differing from either. These differences were not driven in any systematic way by the stimulus properties. There was no indication in the analysis that different groups responded in a qualitatively different way to the manipulations of stimulus length or perceptual difficulty. The differences between groups may have been the result of task demands other than those directly manipulated such as attention and other executive factors. In contrast NWR (i.e., CNrep) performance the SLI/RDI group was significantly different from the groups without RDI due to poorer performance on 4- and 5-syllable nonwords. A possible explanation is that in NWD listeners need to maintain representations of phonological input long enough to discriminate between them, whereas in NWR they need to maintain a representation long enough and with sufficient accuracy for building an output representation to be used for repetition. These different task demands may vary in the degree to which phonological representations are actively maintained in PSTM, which may require engaging both the processes that form phonological representations from speech input and the processes involved in generating phonological representations for speech output. Therefore, a key difference between the tasks may be the extent to which the phonological output system is engaged. The findings of McGettigan, Warren, Eisner, Marshall, Shanmugalingam, and 
Scott's (2010) fMRI may support this view. Their study attempted to uncover the neural correlates of nonword processing under the different task demands of passive listening and active covert rehearsal, while contrasting short or long and phonologically simple or complex nonwords. During covert rehearsal a left-dominant network of temporal and motor cortex showed increased activity for longer items, with motor cortex only showing greater activity to more phonologically complex forms. However, during passive listening the effect of the number of syllables was seen bilaterally in posterior-medial regions of the supratemporal plane, with no evidence of an effect of phonological complexity. Thus, perception and active maintenance of nonwords involved both auditory and motor areas.

The elision and blending tasks of the CTOPP also showed differences between the SLI groups, and while they do not involve nonwords, the listener is required to manipulate and then produce a phonological string. Therefore, again, the tasks require active maintenance of phonological representations and so the engagement of the phonological output system. Thus, for children with SLI plus RDI, the generation and manipulation of representations in the phonological output system may be a key difficulty. In CNRep this is clearest when the task is hard, for longer items, where the phonological output system cannot support accurate repetition and the differences appear between the SLI groups. The metalinguistic demands of phonological awareness put still greater load on the phonological output system resulting in the differences between the SLI groups with and without RDI being stronger. Children with SLI without frank impairments in reading decoding, phonological awareness or nonword repetition perform more poorly on the task than children without spoken language or reading decoding difficulties. On the account suggested here, the explanation for their relatively weak performance is not impairments in the phonological output system but in other cognitive processes engaged by the task, such as attention and other executive factors. 
One strength of this study is the inclusion of a sample of children with severe SLI who did not have RDI with a sample who had both severe SLI and RDI. Another is the use of a range of phonological processing measures which tapped into different levels of the system. A limitation is the sample of children with RDI only was too small to include this group in the analyses and so a possibly illuminating contrast with the SLI/RDI group was lost. In addition the cross-sectional nature of the design only indicates an association in some children with SLI between phonological processing and reading impairment. The direction of the effect has not been established.

Nevertheless, the association between phonological processing and reading decoding impairments in some children with SLI may have clinical implications. Insofar as phonological processing abilities precede the development of reading (Wagner \& Torgesen, 1987), poor phonological processing should alert professionals to the risks to literacy development of impaired reading decoding. Since problems with literacy have a significant detrimental impact on academic success and employment prospects, focussed intervention to improve phonological processing could then be aimed at prevention or reducing these potential problems. More specifically, these results suggest that the emphasis of intervention should be on phonological output processes, for example tasks which involve manipulating speech sounds, rather than on input focused discrimination tasks. Furthermore, in children without phonological processing difficulties, the development of reading skills may allow the use of written language as a means to intervene in language impairment.

In summary, there is a subgroup of children with SLI whose phonological processing is weak. It is proposed here that these deficits are associated with impairments in the part of the phonological system that is required to actively maintain phonological representations for phonological output and is associated with reading decoding difficulties. 


\section{What this paper adds}

What is already known on this subject?

Many children with SLI have phonological processing difficulties, including nonword repetition which is widely seen as a clinical marker of language impairment. These difficulties appear to be associated with reading decoding problems rather than spoken language impairment.

What does this study add?

Phonological processing is measured by a wide range of tasks with varying levels of metacognitive demand. Here, two groups of children with SLI with and without reading decoding difficulties, and a group of TD children, were compared on a series of tasks tapping different levels of phonological processing. The results suggest tasks requiring greater active maintenance of phonological representations for processing distinguish children with SLI with and without reading decoding impairment.

\section{Acknowledgements}

The authors would like to thank the children, parents and school staff who participated in the study and Katarina Dworzynski for her help with data collection. 


\section{REFERENCES}

BAIRD, G., SLONIMS, V., SIMONOFF, E., and DWORZYNSKI, K., 2011. Impairment in non-word repetition: a marker for language impairment or reading impairment? Developmental Medicine and Child Neurology, 53(8), 711-716.

BISHOP, D. V. M., NORTH, T., and DONLAN, C. 1996. Nonword Repetition as a Behavioural Marker for Inherited Language Impairment: Evidence From a Twin Study. Journal of Child Psychology and Psychiatry, 37(4), 391-403.

BISHOP, D. V. M., MCDONALD, D., BIRD, S., and HAYIOU-THOMAS, M. E. 2009. Children Who Read Words Accurately Despite Language Impairment: Who Are They and How Do They Do It? Child Development, 80(2), 593-605.

CATTS, H. W., ADLOF, S. M., HOGAN, T. P., and WEISMER, S. E. 2005. Are Specific Language Impairment and Dyslexia Distinct Disorders? Journal of Speech Language and Hearing Research, 48(6), 1378-1396.

COADY, J. A., KLUENDER, K. R., and EVANS, J. L. 2005. Categorical Perception of Speech by Children With Specific Language Impairments. J Speech Lang Hear Res, (484), 944-959.

GATHERCOLE SE, and PICKERING S. 2001. Working Memory Test Battery for Children. London: Pearson Assessment.

LOUCAS, T., RICHES, N. G., CHARMAN, T., PICKLES, A., SIMONOFF, E., CHANDLER, S., and BAIRD, G. 2010. Speech perception and phonological shortterm memory capacity in language impairment: preliminary evidence from adolescents with specific language impairment (SLI) and autism spectrum disorders (ASD). International Journal of Language and Communication Disorders, 45(3), 275286. 
MARTON, K., and SCHWARTZ, R. G. 2003. Working memory capacity and language processes in children with specific language impairment. Journal of Speech, Language, and Hearing Research: JSLHR, 46(5), 1138-53.

MCGETTIGAN, C., WARREN, J. E., EISNER, F., MARSHALL, C. R., SHANMUGALINGAM, P., and SCOTT, S. K. 2010. Neural Correlates of Sublexical Processing in Phonological Working Memory. Journal of Cognitive Neuroscience, 23(4), 961-977.

MELBY-LERVÅG, M., and LERVÅG, A. 2012. Oral Language Skills Moderate Nonword Repetition Skills in Children With Dyslexia: A Meta-Analysis of the Role of Nonword Repetition Skills in Dyslexia. Scientific Studies of Reading, 16(1), 1-34. MONTGOMERY, J. W. 1995. Examination of Phonological Working Memory in Specifically Language-Impaired Children. Applied Psycholinguistics, 16(4), 355-78. RASHOTTE, C., TORGESEN, J., and WAGNER, R. 1999. Comprehensive Test of Phonological Processing (CTOPP). Austin, TX: Pro-Ed.

ROSEN, S. 2003. Auditory processing in dyslexia and specific language impairment: is there a deficit? What is its nature? Does it explain anything? Journal of Phonetics, 31(3-4), $509-527$.

SEMEL E, WIIG EH, and SECORD W. 2000. Clinical Evaluation of Language Fundamentals, 3rd Edition UK (CELF-3UK). San Antonio, TX: Psychological Corporation.

SEMEL, E., WIIG, E.H., and SECORD, W.A. 2004. Clinical Evaluation of Language Fundamentals -Preschool, 2nd Edition UK (CELF-P UK). San Antonio, TX: Psychological Corporation. 
SNOWLING, M.J. and HULME, C. (2012). Annual Research Review: The nature and classification of reading disorders - a commentary on proposals for DSM-5. Journal of Child Psychology and Psychiatry, 53(5), 593-607.

SPSS 18 2009. SPSS, Inc. Chicago, IL.

TORGESEN, J.K, WAGNER, R.K, and RASHOTTE, C.A. 1999. Test of Word Reading Efficiency (TOWRE). Torrance, CA: WPS.

WAGNER, R.K., and TORGESON, J.K. 1987. The nature of phonological awareness and its Causal role in the acquisition of reading skills. Psychological Bulletin, 101, 192- 212. WECHSLER, D. 1992. The Manual of the Wechsler Intelligence Scale for Children, 3rd edition UK (WISC-III UK). London: The Psychological Corporation. 
Table 1. Descriptive statistics for original and the imputed (EM) complete dataset (standard scores except for NWD where maximum possible score is 40). Analyses conducted with score as the dependent variable and group as the between-subjects factor and family identifier nested within it as a random effect and PIQ and Age as covariates.

\begin{tabular}{|l|l|l|l|l|l|l|l|l|l|l|l|}
\hline & \multicolumn{9}{|l}{ Original dataset } \\
\hline & & NoSLI/NoRD & $(\mathbf{N})$ & SLI/NoRD & (N) & SLI/RDI & (N) & NoSLI/NoRD & SLI/NoRD & SLI/RD \\
\hline Language & & & & & & & & & & & \\
\hline CLS & M & 101.44 & $(18)$ & 67.00 & $(20)$ & 60.64 & $(22)$ & 101.44 & 67.00 & 60.64 \\
\hline & SD & 13.05 & & 8.92 & & 14.43 & & 13.05 & 8.92 & 14.43 \\
\hline RLS & & 102.72 & $(18)$ & 76.80 & $(20)$ & 75.77 & $(22)$ & 102.72 & 76.80 & 75.77 \\
\hline & & 13.42 & & 12.14 & & 14.66 & & 13.42 & 12.14 & 14.66 \\
\hline ELS & & 101.11 & $(18)$ & 62.95 & $(20)$ & 61.10 & $(21)$ & 101.11 & 62.95 & 59.31 \\
\hline & & 13.53 & & 9.49 & & 9.10 & & 13.53 & 9.31 & 12.36 \\
\hline Reading & & & & & & & & & & & \\
\hline $\begin{array}{l}\text { Real word } \\
\text { reading }\end{array}$ & & 96.94 & $(18)$ & 91.55 & $(20)$ & 67.36 & $(22)$ & 96.94 & 91.55 & 67.36 \\
\hline & & 9.10 & & 9.28 & & 12.04 & & 9.10 & 9.28 & 12.04 \\
\hline $\begin{array}{l}\text { Nonword } \\
\text { reading }\end{array}$ & 97.61 & $(18)$ & 95.70 & $(20)$ & 69.55 & $(22)$ & 97.61 & 95.70 & 69.55 \\
\hline & & 13.15 & & 12.41 & & 9.41 & & 13.15 & 12.41 & 9.41 \\
\hline $\begin{array}{l}\text { Phonological } \\
\text { processing }\end{array}$ & & & & & & & & & & \\
\hline NWD & & 35.44 & $(18)$ & 32.00 & $(20)$ & 29.77 & $(22)$ & 35.44 & 32.00 & 29.77 \\
\hline & & 3.82 & & 5.05 & & 6.93 & & 3.82 & 5.05 & 6.93 \\
\hline CNRep & 97.94 & $(17)$ & 90.70 & $(18)$ & 78.18 & $(20)$ & 98.05 & 90.70 & 78.18 \\
\hline & & 12.80 & & 18.92 & & 17.70 & & 12.43 & 18.92 & 17.70 \\
\hline CTOPPpa & 88.25 & $(12)$ & 84.37 & $(19)$ & 63.67 & $(18)$ & 89.78 & 84.59 & 67.11 \\
\hline & & 12.17 & 14.44 & & 6.77 & & 10.65 & 14.09 & 9.80 \\
\hline
\end{tabular}

CLS = CELF Composite Language Score; RLS = CELF Receptive Language Score; ELS = CELF Expressive Language Score; RW Reading = real word reading; NW Reading = nonword reading; NWD = nonword discrimination; CNRep $=$ Children's Test of Nonword Repetition; CTOPPpa = Children's Test of Phonological Processing - phonological awareness 
Table 2. Results of liner mixed effects models using the imputed (EM) complete dataset

(standard scores except for NWD where maximum possible score is 40). Analyses conducted with score as the dependent variable and group as the between-subjects factor and family identifier nested within it as a random effect and PIQ and Age as covariates. (*The models for ELS and NW Reading the random effect variable was redundant and not included in the final model.)

\begin{tabular}{|c|c|c|c|c|c|}
\hline & Group & PIQ & Age & Family & $\begin{array}{l}\text { Pairwise } \\
\text { Comparisons }\end{array}$ \\
\hline CLS & $\begin{array}{l}\mathrm{F}(2,48)=49.968, \\
\mathrm{p}<.001\end{array}$ & $\begin{array}{l}\mathrm{F}(1,53)=17.175, \mathrm{p}< \\
0.001\end{array}$ & $\begin{array}{l}\mathrm{F}(1,54)=5.103, \\
\mathrm{p}=.028\end{array}$ & $\begin{array}{l}\text { Wald } \mathrm{Z}=0.656 \\
\mathrm{p}=.512\end{array}$ & $\begin{array}{l}\text { No-SLI/No-RDI > } \\
\text { SLI/ No-RDI > } \\
\text { SLI/RDI }\end{array}$ \\
\hline RLS & $\begin{array}{l}\mathrm{F}(2,50)=16.773, \\
\mathrm{p}<.001\end{array}$ & $\begin{array}{l}F(1,54)=31.166, p< \\
0.001\end{array}$ & $\begin{array}{l}F(1,54)=0.372, \\
p=.544\end{array}$ & $\begin{array}{l}\text { Wald } Z=0.709, \\
p=.478\end{array}$ & $\begin{array}{l}\text { No-SLI/No-RDI > } \\
\text { SLI/ No-RDI = } \\
\text { SLI/RDI }\end{array}$ \\
\hline ELS* & $\begin{array}{l}F(2,55)=61.835, \\
p<.001\end{array}$ & $\begin{array}{l}F(1,55)=5.415, \\
p=.024\end{array}$ & $\begin{array}{l}F(1,55)=6.063, \\
p=.017\end{array}$ & & $\begin{array}{l}\text { No-SLI/No-RDI > } \\
\text { SLI/ No-RDI = } \\
\text { SLI/RDI }\end{array}$ \\
\hline RW Reading & $\begin{array}{l}F(2,51)=40.855, \\
p<.001\end{array}$ & $\begin{array}{l}F(1,53)=4.130, \\
p=.047\end{array}$ & $\begin{array}{l}F(1,55)=0.838, \\
p=.364\end{array}$ & $\begin{array}{l}\text { Wald } Z=1.119, \\
p=.263\end{array}$ & $\begin{array}{l}\text { No-SLI/No-RDI = } \\
\text { SLI/ No-RDI > } \\
\text { SLI/RDI }\end{array}$ \\
\hline NW Reading* & $\begin{array}{l}F(2,55)=34.715, \\
p<.001\end{array}$ & $\begin{array}{l}F(1,55)=1.422, \\
p=.238\end{array}$ & $\begin{array}{l}F(1,55)=0.582, \\
p=.449\end{array}$ & & $\begin{array}{l}\text { No-SLI/No-RDI = } \\
\text { SLI/ No-RDI > } \\
\text { SLI/RDI }\end{array}$ \\
\hline NWD & $\begin{array}{l}F(2,51)=3.937 \\
p=.026\end{array}$ & $\begin{array}{l}F(1,30)=1.069 \\
p=.309\end{array}$ & $\begin{array}{l}F(1,48)=5.446, \\
p=.024\end{array}$ & $\begin{array}{l}\text { Wald } Z=2.755, \\
p=.006\end{array}$ & $\begin{array}{l}\text { No-SLI/No-RDI = } \\
\text { SLI/ No-RDI; No- } \\
\text { SLI/No-RDI > } \\
\text { SLI/RDI; SLI/ No- } \\
\text { RDI = SLI/RDI }\end{array}$ \\
\hline CNRep & $\begin{array}{l}F(2,49)=6.976, \\
p=.002\end{array}$ & $\begin{array}{l}F(1,41)=0.083, \\
p=.774\end{array}$ & $\begin{array}{l}F(1,54)=1.808, \\
p=.184\end{array}$ & $\begin{array}{l}\text { Wald } Z=1.581, \\
p=.114\end{array}$ & $\begin{array}{l}\text { No-SLI/No-RDI = } \\
\text { SLI/ No-RDI > } \\
\text { SLI/RDI }\end{array}$ \\
\hline СТОРРра & $\begin{array}{l}\mathrm{F}(2,50)=19.856, \\
\mathrm{p}<.001\end{array}$ & $\begin{array}{l}F(1,15)=0.891, \\
p=.360\end{array}$ & $\begin{array}{l}F(1,32)=2.132, \\
p=.138\end{array}$ & $\begin{array}{l}\text { Wald } Z=2.864, \\
p=.004\end{array}$ & $\begin{array}{l}\text { No-SLI/No-RDI = } \\
\text { SLI/ No-RDI > } \\
\text { SLI/RDI }\end{array}$ \\
\hline
\end{tabular}

CLS = CELF Composite Language Score; RLS = CELF Receptive Language Score; ELS = CELF Expressive Language Score; RW Reading = real word reading; NW Reading = nonword reading; NWD = nonword discrimination; CNRep $=$ Children's Test of Nonword Repetition; CTOPPpa = Children's Test of Phonological Processing - phonological awareness 
Table 3. Nonword discrimination number correct (out of 10) for each condition.

\begin{tabular}{l|llll} 
& & \multicolumn{3}{c}{ Diagnostic group } \\
\cline { 2 - 5 } Stimulus type & & No-SLI/No-RDI & SLI/No-RDI & SLI/RDI \\
\hline 2-Syllable/Initial & Mean & 9.4 & 8.7 & 8.1 \\
& SD & 0.9 & 1.3 & 1.5 \\
2-Syllable/Medial & & 8.4 & 7.8 & 7.6 \\
& & 1.1 & 1.4 & 1.6 \\
4-Syllable/Initial & & & 7.7 & 7.0 \\
& & 1.4 & 1.6 & 2.2 \\
4-Syllable/Medial & & & & 7.2 \\
& & 1.9 & 7.9 & 2.5
\end{tabular}


Figure 1. CNRep scores (with 95\% confidence intervals).

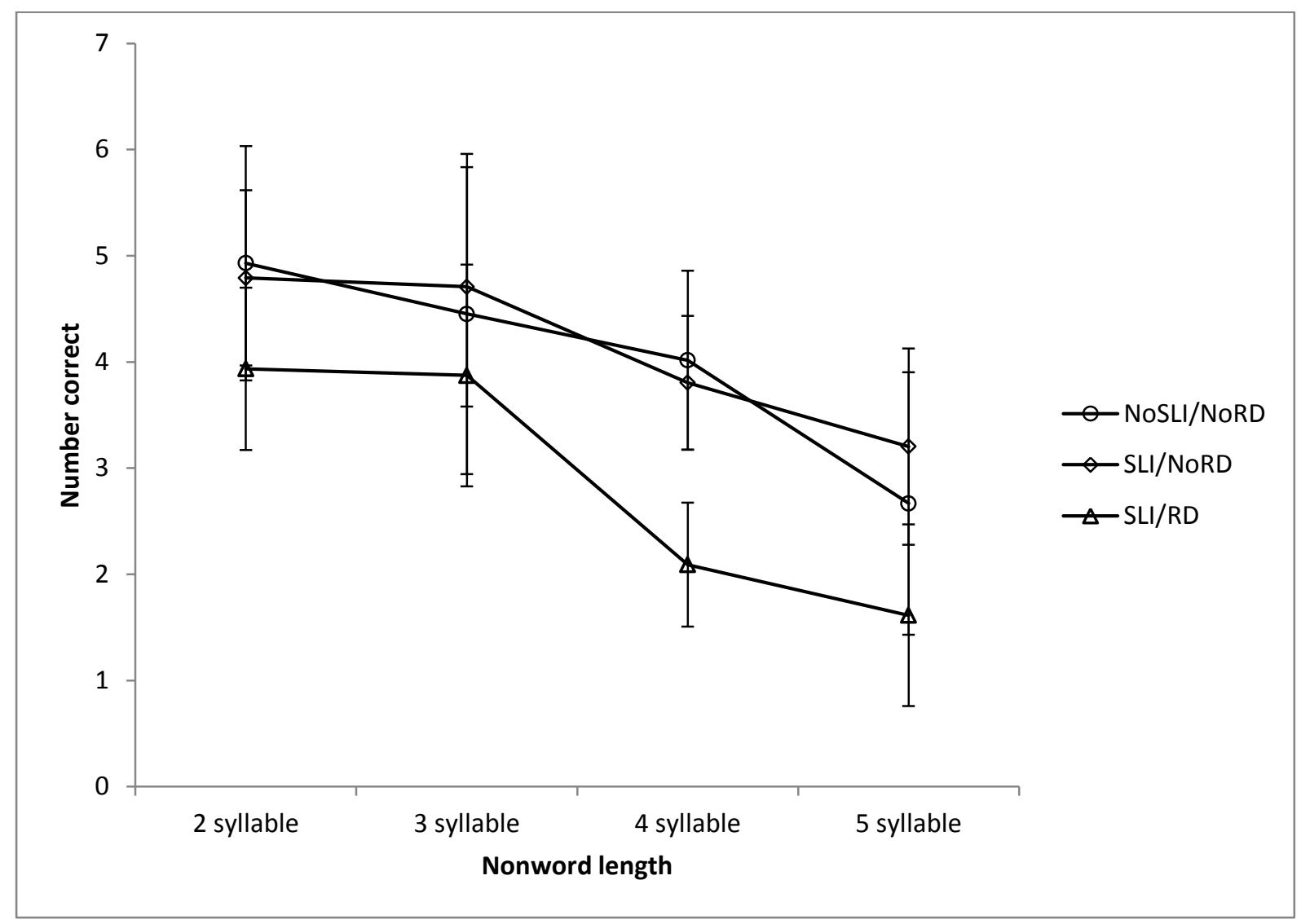

